\title{
Eccentric training for elbow hypermobility
}

\author{
JF Kaux ${ }^{1}$, F Delvaux ${ }^{1}$, B Forthomme ${ }^{1}$, M Foidart-Dessalle ${ }^{1}$, \\ FG Debray², JM Crielaard ${ }^{1}$, JL Croisier $^{1}$
}

1. Physical Medicine and Rehabilitation Department, CHU Sart-Tilman, Université de Liège, 4000 Liège, Belgium.

2. Human Genetics Department, CHU Sart-Tilman, Université de Liège, 4000 Liège, Belgium.

\section{Background:}

Patients with hypermobility suffer from joints problems and chronic pain is the most frequently reported symptom.

Objective:

Eccentric muscle strengthening could be very important to protect hypermobile joints.

Design:

Case report.

\section{Patient:}

A girl (16 y.o.) affected by an Ehler-Danlos syndrome presented pain in the right elbow (Fig. 1) and the right wrist (Fig. 2) after a season of tennis.

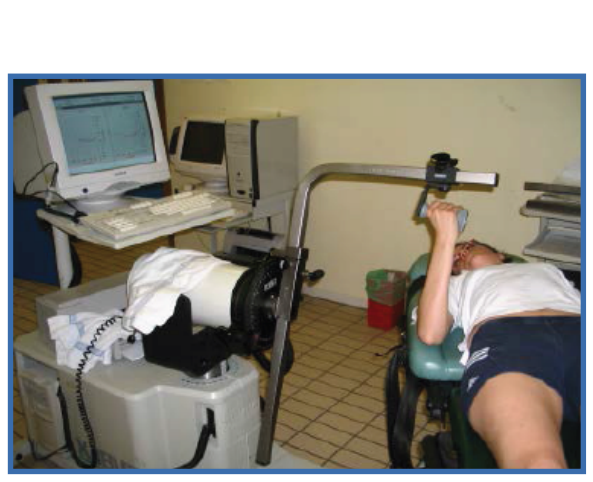

Fig. 3

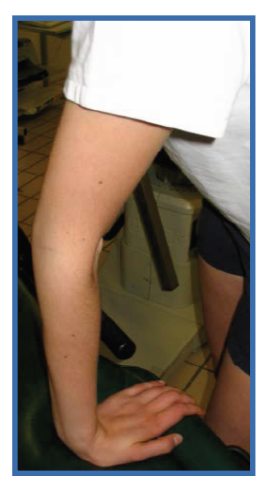

Fig. 1

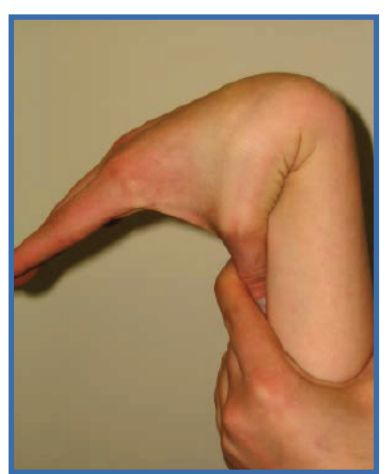

Fig. 2

\section{Interventions:}

Her training (18 sessions, 3 times a week) consisted of wrist prono-supination and flexion-extension muscle group reinforcement and proprioceptive training. To protect the wrist against excessive load, the eccentric strengthening exercises of prono-supinator and flexor-extensor muscles of elbow and wrist were undertaken gradually, at increasing speeds within a limited range of motion in flexion and extension, on an isokinetic device after an evaluation (Fig. 3). She was also given an orthesis restricting the joint range of motion of the wrist

Main outcome measurements:

The evaluation was made by isokinetic evaluation, visual analog scale and MOSSF36 questionnaire before and after training.

\section{Results:}

The patient rapidly noted a decrease in pain and an increase in the stability of her right arm even when playing tennis. Isokinetic evaluation objectified an improvement in maximal torque of 20 to $25 \%$ in flexion-extension muscles of the right elbow (Table 1). She was also given individualized home exercises.

\begin{tabular}{|c|c|c|c|}
\hline \multirow{2}{*}{ Test procedures (concentric) } & \multicolumn{3}{|c|}{ Peak torque (N.m) } \\
\cline { 2 - 4 } & $\begin{array}{c}\text { Left elbow } \\
\text { (control) }\end{array}$ & $\begin{array}{c}\text { Right elbow (pathological) } \\
\text { Pre-test }\end{array}$ & $\begin{array}{c}\text { Right elbow (pathological) } \\
\text { Post-test }\end{array}$ \\
\hline Flexion $60^{\circ} / \mathrm{s}$ & 30 & 22 & 28 \\
\hline Flexion $180^{\circ} / \mathrm{s}$ & 25 & 16 & 19 \\
\hline Extension $60^{\circ} / \mathrm{s}$ & 31 & 26 & 32 \\
\hline Extension $180 \%$ & 25 & 22 & 26 \\
\hline
\end{tabular}

Table 1

\section{Conclusions:}

The goal of this eccentric training is to avoid hypermobility by using the muscles as a protective brake in the control of joint positioning. Muscles can be reinforced in eccentric mode with starting position at the maximum length of these muscles when unstreched. The exercises can be carried out safely on an isokinetic device, at slow speed and limited range of joint motion to avoid risk of luxation. Thus, in this case report, the eccentric exercises using an isokinetic device were effective to safely reinforce the muscles as a protective brake for joint hypermobility and prevent pain during practicing tennis.

\section{References:}

Kaux J.-F., Forthomme B., Foidart-Dessalle M., Delvaux F., Debray F.-G., Crielaard J.-M., Croisier J.-L. (2013). Eccentric rehabilitation for elbow hypermobility. Journal of Novel Physiotherapies, 3(6), 180 (5 pages).

Kaux J.-F., Foidart-Dessalle M., Croisier J.-L., Toussaint G., Forthomme B., Crielaard, J.-M. (2010). Physiotherapy Intervention for Joint Hypermobility in Three Cases with Heritable Connective Tissue Disorders. Journal of Musculoskeletal Pain, 18(3), 254-60. 